\title{
Inhibition of Migration, Invasion and Drug Resistance of Pancreatic Adenocarcinoma Cells - Role of Snail, Slug and Twist and Small Molecule Inhibitors
}

This article was published in the following Dove Press journal:

OncoTargets and Therapy

\author{
Ezgi Kașıkcı (D) ${ }^{1,2}$ \\ Esra Aydemir (D) \\ Ömer Faruk Bayrak ${ }^{3}$ \\ Fikrettin Șahin' \\ 'Department of Genetics and \\ Bioengineering, Faculty of Engineering \\ and Architecture, Yeditepe University, \\ Istanbul 34755, Turkey; ${ }^{2}$ Department of \\ Microbiology and Immunology, Albert \\ Einstein College of Medicine, Bronx, NY \\ 1046I, USA; ${ }^{3}$ Department of Medical \\ Genetics, Yeditepe University Medical \\ School and Yeditepe University Hospital, \\ Istanbul 347/8, Turkey
}

Correspondence: Ezgi Kașıkcı Email ezgikasikcil3@gmail.com
Purpose: The main purpose of this study is to demonstrate the effects of epithelial to mesenchymal transition activating transcription factor silencing (EMT-ATF silencing) on migration, invasion, drug resistance and tumor-forming abilities of various pancreatic cancer cell lines. Additionally, the contribution of small molecule inhibitors of EMT (SD-208 and CX4945) to the effects of gene silencing was evaluated.

Methods: EMT activating transcription factors "Snail, Slug and Twist" were silenced by short hairpins on Panc-1, MIA PaCa-2, BxPC-3, and AsPC-1 pancreatic cancer cell lines. The changes in migration, invasion, laminin attachment, cancer stem-like cell properties and tumor-forming abilities were investigated. Chemosensitivity assays and small molecule inhibitors of EMT were applied to the metastatic pancreatic cancer cell line AsPC-1.

Results: EMT-ATF silencing reduced EMT and stem cell-like characteristics of pancreatic cancer cell lines. Following EMT-ATF silencing amongst the four PC cell lines, AsPC-1 showed the best response and was chosen for further chemoresistance and combinational therapy applications. EMT downregulated AsPC-1 cells showed less resistance to select chemotherapeutics compared to the control group. Both small molecule inhibitors enhanced the outcomes of EMT-ATF silencing.

Conclusion: Overall it was found that EMT-ATF silencing, either by EMT-ATF silencing or with the enhancement by small molecules, is a good candidate to treat pancreatic cancer since it simultaneously minimizes metastasis, stem cell properties, and drug resistance.

Keywords: pancreatic cancer, metastasis, cancer, EMT, gene therapy, anti-cancer drug

\section{Introduction}

Pancreatic Cancer (PC) is the fourth most prominent cause of cancer-related mortality in the United States and is increasing in prevalence. ${ }^{1}$ The fact that symptomatic presentation of pancreatic cancer in the clinical setting often overlaps with that of other diseases, combined with frequent failure of screening methods to detect this type of malignancy in early stages, decreases the chance of diagnosis significantly. $^{2}$ In later stages, the resistance of pancreatic cancer to many chemotherapeutic agents results in poor response to conventional therapy and is, therefore, a major cause of high mortality. ${ }^{3}$ However, for most pancreas cancer patients, the major risk stems from the high metastasis potential. ${ }^{4}$

Increasing incidence, combined with the current incurability of pancreatic cancer, is leading researchers to pursue new chemotherapeutics, ${ }^{5}$ gene therapy for drug effectiveness $^{6}$ and other novel approaches to control pancreatic cancer metastasis. ${ }^{7}$ 
Susceptibility to metastasis and the aggressiveness of pancreas cancer is caused by a high presence of cancer stem cells within the tumor and activated metastatic pathways. ${ }^{8}$ While still under-researched, Epithelial to Mesenchymal Transition (EMT) is accepted as an essential factor for increased metastasis, cancer stemness and tumor growth. ${ }^{9}$ By regulating EMT, it may be possible to control CSCs and metastasis, and therefore the aggressiveness of pancreas cancer. ${ }^{10}$

EMT and its reverse process MET (Mesenchymal to Epithelial Transition) are controlled by many pathways, including WNT, PI3K/AKT and Notch signaling. ${ }^{11}$ The main pathway regulating the transcription factor activators of EMT and MET is the TGF- $\beta$ pathway. ${ }^{12}$ End products of the TGF- $\beta$ pathway, which are mainly transcription activators, repress epithelial marker genes while activating mesenchymal markers. The changes in the expressions of transcription factors Snail, Slug and Twist-1 repress the expressions of E-cadherin, Claudins, Cytokeratins and Plakophilin, while also upregulating the expressions of many factors controlling EMT, including Fibronectin, N-Cadherin, Collagen, MMP15, MMP2, MMP9 and ZEB1-2. ${ }^{11}$

Small molecule inhibitors are low molecular weight organic compounds that control biological processes and inhibit functions of kinases and receptors. SD-208, a small molecule inhibitor of TGF- $\beta$ receptor I kinase (T $\beta R I)$, was previously found to decrease melanoma bone metastasis. ${ }^{13}$ Another small molecule, CX4945, an inhibitor of protein kinase CK2 and a downstream effector of the TGF- $\beta$ pathway, ${ }^{14}$ is shown to inhibit the pro-survival and angiogenesis of breast cancer. ${ }^{15}$ These small molecules may be considered as potential agents to inhibit metastasis of the pancreatic tumor due to TGF- $\beta$ being the main controller of EMT transcription factors.

In this study, we target Snail, Slug and Twist-1 genes in pancreatic cancer cell lines which have different metastatic and drug resistance characteristics. The selected cell lines are Panc-1 (Pancreas/duct epithelioid carcinoma), MIA PaCa-2 (Pancreas carcinoma), BxPC-3 (Pancreas adenocarcinoma) and AsPC-1 (metastatic pancreatic adenocarcinoma). We aim to understand how silencing these genes affect cell migration, invasion, attachment to laminin, cancer stemness and drug resistance. Furthermore, we investigate the potential of the two small molecule inhibitors, when combined with gene therapy, as an alternative approach for treating metastatic pancreatic cancer. Our findings suggest that EMT-ATF silencing, either with gene therapy or small molecule inhibition, leads to better prognosis in pancreatic cancer cell lines.

\section{Materials and Methods Cell Culture and Stable Transfection of Pancreas Cancer Cell Lines}

Pancreatic cancer (PC) cell lines, Panc-1, MiaPaCa-2, BxPC3, AsPC-1, and healthy immortalized pancreas cell line, hTERT-HPNE, were obtained from the American Type Culture Collection (ATCC, USA). AsPC-1 and BxPC-3 cells were cultured in RPMI 1640 medium supplemented with 10\% FBS and 1\% antibiotic (Thermo-Fisher Scientific, USA), while MiaPaCa-2 and Panc-1 cells were cultured in DMEM with $10 \%$ FBS and $1 \%$ antibiotic. The hTERT-HPNE cells were cultured in a special medium containing one volume of M3 base (InCell Corp., San Antonio, TX, USA), three volumes of glucose-free Dulbecco's modified Eagle's medium, 5\% fetal bovine serum (FBS), $5.5 \mathrm{mM}$ glucose, $10 \mathrm{ng} / \mathrm{mL}$ epidermal growth factor (EGF) and 750 $\mathrm{ng} / \mathrm{mL}$ puromycin. Cells were cultured in a humidified atmosphere $\left(5 \% \mathrm{CO} 2\right.$ at $\left.37^{\circ} \mathrm{C}\right)$ and monitored for their typical morphology to prevent cross-contamination.

\section{shRNA Lentiviral Particle Transfection}

Short hairpin lentiviral particles Snail (sc-38398-V), Slug (sc-38394-V), Twist-1 (sc-38604-V), copGFP shRNA control (sc-108084) and control shRNA (sc-108080) was purchased from Santa Cruz, USA. Transfection was performed as given in the manufacturer's protocol. Briefly, cells were seeded in 12-well plates and incubated overnight for attachment. The culture medium was replaced with the transfection medium containing $5 \mu \mathrm{g} / \mathrm{mL}$ polybrene (sc-134220, Santa Cruz, USA). Lentiviral particles were added to the culture in pre-optimized MOI values. Cells were incubated for $24 \mathrm{hrs}$ and the culture medium was renewed or cells were split into 1:3. After 5 days of transfection, GFP was observed, and the medium was changed with a complete medium containing $1 \mu \mathrm{g} / \mathrm{mL}$ puromycin dihydrochloride (sc-108071, Sigma Aldrich, USA) for Panc-1, BxPC-3, AsPC-1 and $2 \mu \mathrm{g} / \mathrm{mL}$ for MIA PaCa-2 cells. Puromycin-resistant colonies were selected. Transfected cells were cultured continuously without freezing to eliminate the possible loss of gene silencing in repeated freeze-thaw cycles.

\section{RNA Isolation and Reverse Transcription-Polymerase Chain Reaction (RT-PCR)}

Total RNA was extracted using High Pure RNA Isolation Kit (11828665001, Roche Life Science, USA) and cDNAs 
were synthesized by QuantiTect ${ }^{\circledR}$ Reverse Transcription Kit (205313, Qiagen, USA) as instructed by the manufacturers. Changes in gene expression after EMT-ATF silencing were evaluated by qPCR conducted with TaqMan ${ }^{\circledR}$ Fast Universal PCR Master Mix (4352042, Thermo Scientific, USA) with the TaqMan probes, listed in Supplementary Table 1A, as described in the manufacturer's protocol. Expression analysis for genes related to drug resistance and survival were evaluated with the TaqMan probes, listed in Supplementary Table 1B, as described in the manufacturer's protocol. Expression analysis after the small molecule inhibitor treatment was conducted with TaqMan ${ }^{\circledR}$ Fast Universal PCR Master Mix (4352042, Thermo Scientific, USA) and SYBR ${ }^{\mathrm{TM}}$ Select Master Mix (4472908, Thermo Scientific, USA) as described ${ }^{16}$ with TaqMan Probes and customized primers; listed in Supplementary Table 1C. Expression values were normalized to GAPDH (Supplementary Table 1D) and a relative fold-change in expression with respect to a reference sample was calculated using the 2- $\Delta \Delta \mathrm{Ct}$ method. Results were analyzed with a CFX96 Touch $^{\mathrm{TM}}$ Real-Time PCR Detection System (Bio-Rad, USA) and CFX Manager Software (V.3.0, Bio-Rad, USA).

\section{Protein Analysis}

Changes in protein levels after gene therapy were examined with ELISA Assay. Briefly, proteins were isolated with RIPA Buffer (R0278, Sigma, USA) containing 1x Halt ${ }^{\mathrm{TM}}$ Protease Inhibitor Cocktail (78430, Thermo Scientific, USA). Protein concentrations were measured using Pierce ${ }^{\mathrm{TM}}$ BCA Protein Assay Kit (23227, Thermo Scientific, USA). Protein concentration analyses were conducted with human Snail homolog $1(\mathrm{E} 3964 \mathrm{H})$, human Snail homolog 2 (E1877H) and human Twist related protein (Twist1) $(\mathrm{E} 3531 \mathrm{H})$, as described in the manufacturer's protocol (BT Laboratories, China). Results were normalized to GAPDH (E0704Hu). Colorimetric results were analyzed in an ELx800 96-well Microplate Reader (MTX Lab Systems, USA).

\section{Scratch Assay}

Cells were seeded to the wells of a 12-well tissue culture plate to a final density of $80 \%$ confluence. Cells were then scraped with a $100 \mu \mathrm{L}$ sterile pipette tip to leave a straight line. Detached cells were removed and the serum concentration of the culture medium was reduced to $2 \%$ to keep the cells less proliferative. ${ }^{17}$ Wound healing was monitored by taking images at 0, 24, 48 and $72 \mathrm{hrs}$. Images were taken by an inverted microscope (ZEISS Axio Vert.A1, Zeiss, Germany) and evaluated using Image J, MiToBo plugin (ImageJ Software, NIH, USA).

\section{Invasion and Migration Assay}

Invasion and Migration assay was conducted by CytoSelect ${ }^{\mathrm{TM}}$ 24-Well Cell Migration and Invasion Assay (CBA-100-C, Cell Biolabs, CA, USA). Cells in pre-optimized numbers were seeded on the upper surface of migration and invasion inserts in a $300 \mu \mathrm{L}$ serum-free cell culture medium. Lower well of the migration plate was filled with $500 \mu \mathrm{L}$ culture media with $10 \%$ FBS. Inserts were cultured in a humidified atmosphere $(5 \%$ $\mathrm{CO} 2$ at $37^{\circ} \mathrm{C}$ ) for $24 \mathrm{hrs}$ for migration and $48 \mathrm{hrs}$ for invasion assay. The medium of the insert was aspirated and nonmigratory/invasive cells were removed with a cotton-tipped swab. Cells were stained with cell stain solution, rinsed in $\mathrm{dH}_{2}$ $\mathrm{O}$ and dried. Migrated and invaded cells were counted with an inverted microscope (ZEISS Axio Vert.A1, Zeiss, Germany). Cellular images were analyzed using Image $\mathbf{J}$ cell counter (ImageJ Software, NIH, USA).

\section{Tumor Sphere Formation Assay}

Cells were seeded at $1 \times 10^{3}$ cells/well on ultra-low attachment 6-well plates. Cells were then cultured in the sphere formation medium described by Gaviraghi et al. ${ }^{18}$ The medium was replenished every 2 days until spheres reach a diameter of $50-130 \mu \mathrm{M}$. Spheres were counted and average numbers from each knockdown were compared to their control cells.

\section{Attachment to Laminin}

The 96-well plates were coated with Laminin proteins $\left(1 \mu \mathrm{g} / \mathrm{cm}^{2}\right)$ and incubated for $45 \mathrm{mins}$ at $37^{\circ} \mathrm{C}$. The solution was then removed and plates were incubated at room temperature until dried. Cells were seeded at $1 \times 10^{3}$ cells/ well and incubated in culture medium at $37^{\circ} \mathrm{C}$ for 30 mins. Non-attached cells were removed and attached cells were stained with crystal violet $(0.5 \%)$. Excess dye was removed with gentle PBS washes and dye trapped within the cells was extracted with acetic acid (33\%). Absorbance values were measured at 560 by ELx800 96-well Microplate Reader (MTX Lab Systems, USA).

\section{Flow Cytometric Analysis of PC CSC Markers}

PC cells, grown in the normal culture medium, were harvested, washed with PBS and re-suspended in $100 \mu \mathrm{L}$ of PBS containing $0.5 \%$ bovine serum albumin and $2 \mathrm{mM}$ 
EDTA. Antibodies for CD133/1-FITC (130-105-226, Milentyi, Germany), CD24-FITC (130-095-952, Milentyi, Germany), CD44-PE (130-095-180, Milentyi, Germany), CD184 (CXCR4)-Alexa fluor 488 (53-9991-80, Thermo Fisher Scientific, USA) were added to the solution at a $1 \mu \mathrm{L} / 10^{6}$ cells and incubated. Cells were then washed with the buffer and re-suspended in $200 \mu \mathrm{L}$ buffer for analysis with flow cytometry (BD FACSCalibur, BD Biosciences, San Jose, CA).

\section{Drug Resistance and Cellular Viability}

hTERT-HPNE cells and AsPC-1 cells were grown and seeded in 96 -well plates at $5 \times 10^{3}$ cells/well. Cells were then treated with $200 \mu \mathrm{M}, 100 \mu \mathrm{M}, 50 \mu \mathrm{M}$ and $25 \mu \mathrm{M}$ 5-Fluorouracil (F6627, Merck, Germany) and $0.8 \mu \mathrm{M}, 0.4$ $\mu \mathrm{M}, 0.2 \mu \mathrm{M}, 0.1 \mu \mathrm{M}$ Mitomycin C (M4287, Merck, Germany) for 48 hrs. After 48 hrs, cells were subjected to MTS cellular viability assay as described by Tominaga et al. ${ }^{19}$ Absorbance values were measured at $490 \mathrm{~nm}$ with ELx800 96-well Microplate Reader (MTX Lab Systems, USA).

\section{Combination Therapy}

AsPC-1 shSnail, shSlug, shTwist and shControl cells were treated with SD208 and CX4945 at previously found nontoxic doses (data not shown). Briefly, cells were harvested and seeded into T25 flasks and cultured overnight. The medium was replaced with serum-free medium overnight. The medium was replaced with serum free RPMI supplemented with $5 \mathrm{ng} / \mathrm{mL}$ TGF- $\beta$ containing either $10 \mu \mathrm{M} \mathrm{CX} 4945$ or $200 \mu \mathrm{M}$ SD208. After $48 \mathrm{hrs}$ of incubation, cells were collected for RNA isolation, invasion and migration assay.

\section{Statistical Analysis and Image Processing}

All the experiments were performed at least three times independently and the data were subjected to unpaired two-tailed Student's $t$-test or one-way ANOVA accompanied by Tukey's post-test where appropriate. $\mathrm{p}<0.05$ was considered statistically significant and defined with an asterisk. For migration and invasion assays, cells were counted with Image $\mathrm{J}^{20}$ and analysis of scratch assay was done with ImageJ-Mi ToBo Plugin. ${ }^{21}$

\section{Results}

\section{Silencing Snail, Slug and Twist-I Reduces Cellular Migration Ability in PC Cells}

Migration is the prerequisite of metastasis and EMT regulates migration pathways. Cells were transfected with short hairpin lentiviral particles for Snail, Slug and Twist-1. EMT-ATF silencing was confirmed with qPCR and ELISA analyzes (Supplementary Figure 1). To investigate the migratory effects of EMT-ATF silencing in vitro, wound healing and transwell migration assays were performed. The assessment of the wound healing assay reveals that the migration ability of the cells decreased significantly in 72 hrs (Figure 1).

As shown in Supplementary Figure 2, control cells migrated to close the wound over 72 hrs; however, Snail, Slug and Twist silencing repressed the cell migration. Transwell migration assay also showed that EMT-ATF silencing reduced the growth factor-induced directional migration of PC cells (Figure 2).

\section{Silencing Snail, Slug and Twist-I Decreases the Invasiveness and Ability to} Attach to Laminin of PC Cells

Invasion and attachment to ECM are the major indicators of metastasis. EMT is a key regulator of invasive pathways. To evaluate the contributions of Snail, Slug and Twist-1 knockdown on invasion of PC cells, transmembrane invasion assay was conducted. Cellular invasion amount was significantly decreased with EMT-ATF silencing compared to control cells (Figure 3).

To evaluate the change in laminin attachment ability and the malignancy potential, attachment to laminin assay was performed. Laminin attachment in a limited time, 30 mins, was decreased in the cells with EMT-ATF silencing compared to cells transfected with control lentiviral particles (Figure 4).

\section{EMT-ATF Silencing Suppresses Cancer Stem-Like Cell Markers and Reduces Sphere Formation Ability}

Epithelial to mesenchymal transition has a major role in cancer stemness. To investigate the roles of Snail, Slug and Twist- 1 on cancer stemness, expressions of cancer stem cell markers specific to pancreatic cancer, qPCR and flow cytometry analyses were performed on EMT silenced cells. Compared to control cells, gene expressions of cancer stem cell markers CD133, CD24, CD44, EpCAM, CXCR4 and c-MET were significantly decreased. Reduction in protein levels was also confirmed with flow cytometry. The amount of CD24+, 


\section{Panc-1}

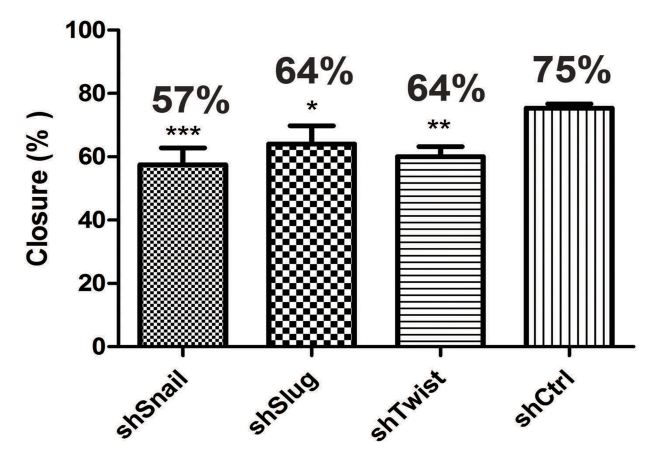

BXPC-3

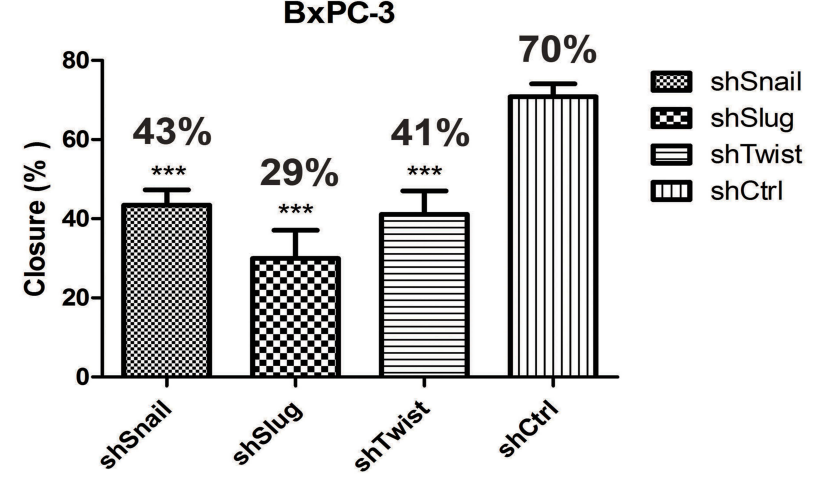

MIA PaCa-2
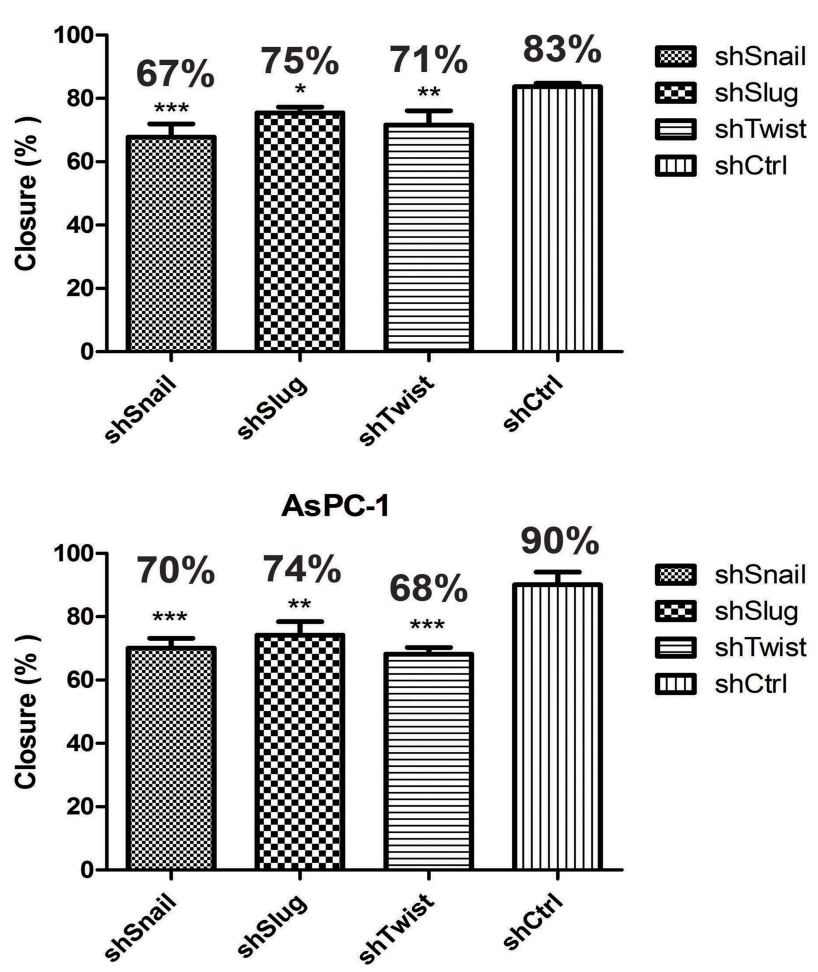

Figure I Snail, Slug and Twist downregulation suppress cell migration. Wound healing assay was done with EMT-ATF silenced Panc-I, MIA PaCA-2, BxPC-3 and AsPC-I. Compared to other cells, EMT-ATF silenced BxPC-3 and AsPC-I cells showed less migratory behavior as against their negative controls $(* \mathrm{P}<0.05$, $* * \mathrm{P}<0.0 \mathrm{I}$ and $* * * \mathrm{p}<0.00 \mathrm{I})$.

CD44+, CD133+ and CXCR4+ cells were significantly decreased (Figure 5).

In Figure 5 and Supplementary Table 2, relative expression amounts of stated genes were represented. Flow cytometry results are given in Supplementary Figure 3 and Supplementary Figure 4.

We also examined the effect of EMT-ATF silencing on the expression of EMT associated genes (E-cadherin, $\mathrm{N}$-cadherin and Vimentin), stemness-associated transcription factors (KLF4, Sox2, Nanog and Oct4) and matrix metalloproteinase-1 (MMP1) by qPCR (Supplementary Figure 5). It was shown that EMT-ATF silencing led to an increase of the epithelial marker E-cadherin, whereas a decrease in mesenchymal markers $\mathrm{N}$-cadherin and Vimentin was observed. Along with EMT markers, expression levels of matrix metalloprotease-1 were decreased in all treated PC cell lines. Expressions of pluripotency markers, especially Oct4, Nanog and Sox2, were significantly reduced with EMT-ATF silencing.

Stem-like cells in a tumor population have the ability to reform the entire tumor under non-adherent conditions. In this study, EMT-ATF silenced PC cells lost their ability to re-initiate tumor spheres compared to their control groups (Figure 6). An average number of spheres per well were found to be lower, especially in AsPC-1 cells.

\section{EMT-ATF Silencing Decreased the Drug Resistance}

Healthy immortalized hTERT-HPNE cell line was used as a healthy reference to AsPC-1 cell line to determine the highest non-lethal dose of selected drugs (Supplementary Figure 6). Chosen concentrations for 5-Fluorouracil and Mitomycin $\mathrm{C}$ are $200 \mu \mathrm{M}$ and $0.8 \mu \mathrm{M}$, respectively. Drug treatment has decreased the viabilities of EMT silenced AsPC-1 cells down to $16 \%$, while the viabilities of control groups were only down to $80 \%$ (Figure $7 \mathrm{~A}$ ).

EMT-ATF silencing controls the drug resistance of cancer cells. The decrease in Snail, Slug and Twist expressions concordantly decreased the expressions of drug resistance and survival genes (Survivin, Muc1 and ABCG2) (Supplementary Figure 7). 5-Fluorouracil and Mitomycin-C treatment to EMT silenced AsPC-1 cells caused a further decrease in gene expression levels of Survivin, Muc1 and ABCG2 (Figure 7B-C). 
A

Panc-1

MIA

PaCa-2

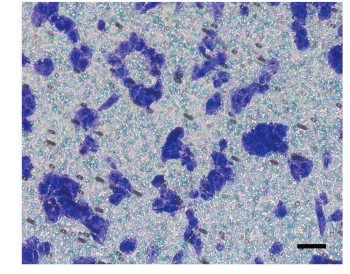

BXPC-3
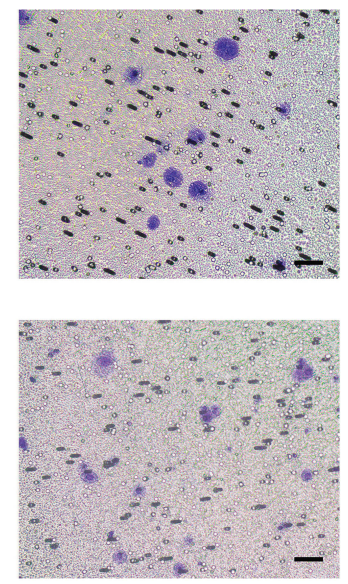
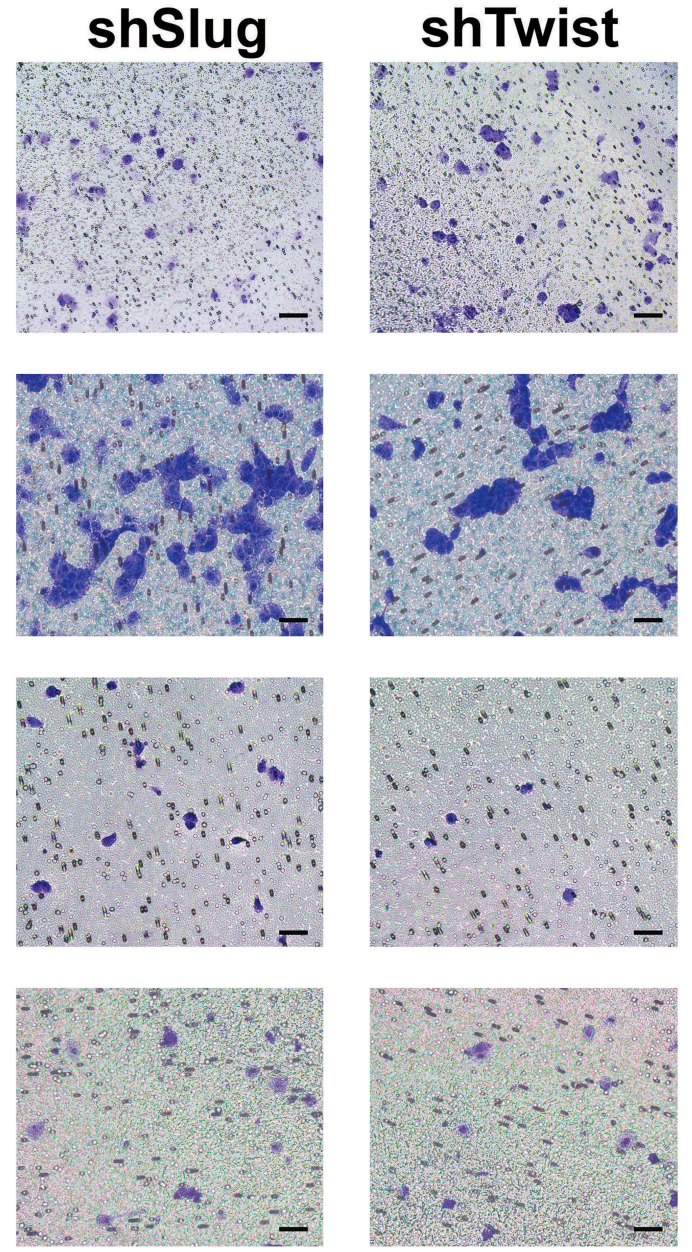

shControl
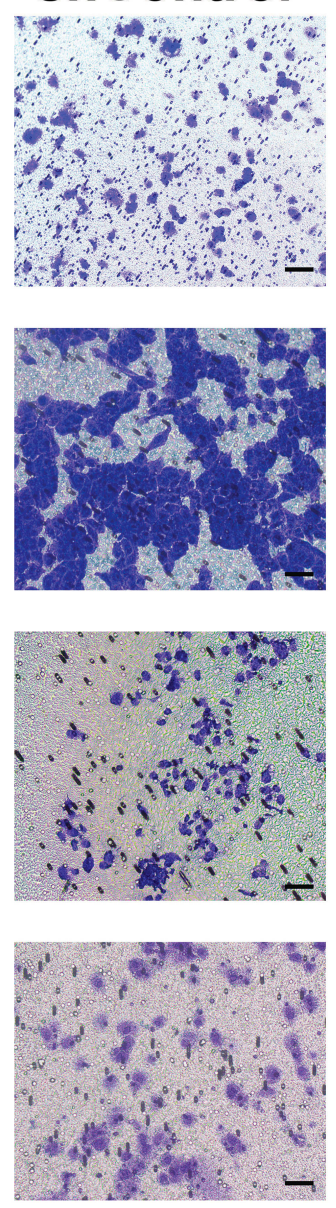

B

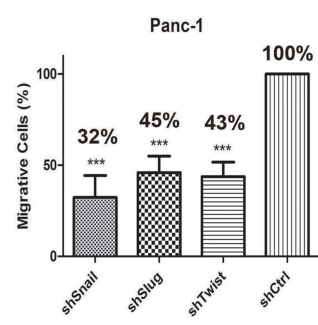

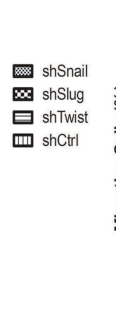

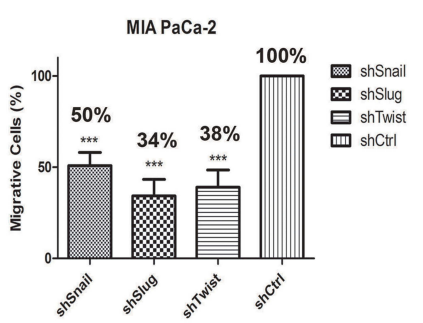

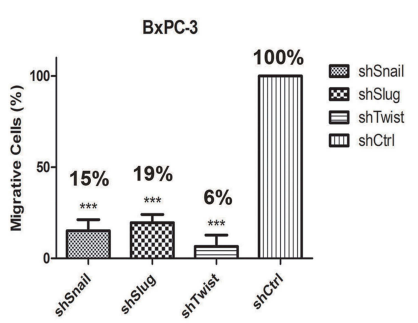

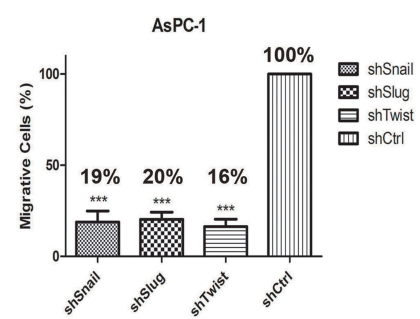

Figure 2 Snail, Slug and Twist downregulation attenuate transmembrane migration. (A) Cellular images of cells that passed through the membrane (100x magnification). Cells were counter-stained, and three random areas were counted. (B) Graphical representations of relative percentages of migratory cell counts after 24 hrs. Silenced cells show a less tendency towards transmembrane migration compared to control. Migration was significantly decreased at least to $50 \%$ after gene silencing ( $* * * p<0.00 \mathrm{I}$ ). Scale bar represents $100 \mu \mathrm{m}$.

Combination of Small Molecules and Snail, Slug, has a Substantial Effect on the Progression and Metastasis of AsPC-I Cells Small molecules can be used to enhance the effects of EMTATF silencing. In our study, we used two small molecule inhibitors of EMT (SD208 and CX4945) along with EMTATF silencing to evaluate the efficacy of combinational therapy on PC cells. Following the treatment with small molecules, Snail and Slug silenced AsPC-1 cells expressed lower amounts of EMT (expression data not shown), pluripotency (expression data not shown), metastasis, and pancreatic cancer-related stemness markers (Supplementary Figure 8) compared to Twist silenced AsPC-1 cells. Therefore, further investigation was done on migration and invasion of Snail and Slug silenced AsPC-1 cells. It was found that, together with gene silencing, small 


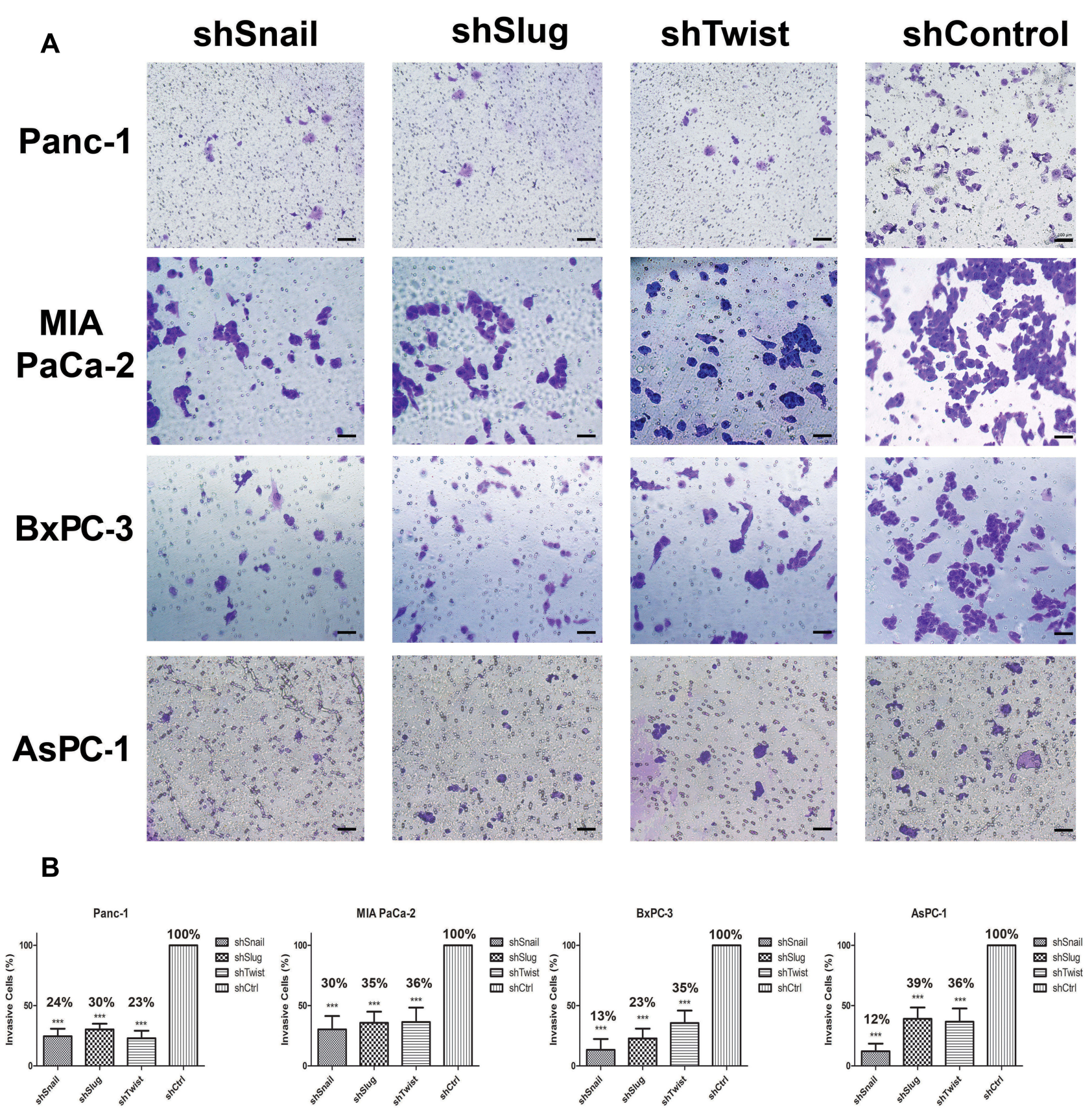

Figure 3 Snail, Slug and Twist expression lessen invasiveness. (A) Microscope images of invasive cells that passed through the Matrigel (I00x magnification). (B) Graphical representation of the percentage of invasive cells shows the relative percentages of invasive cells. The number of invaded cells significantly decreases with EMT-ATF silencing $(* * * p<0.0-1)$. Scale bar represents $100 \mu \mathrm{m}$.

molecule inhibition of the EMT pathway decreases the migration and invasion values significantly more compared to gene silencing alone (Figure 8).

\section{Discussions}

Despite the improvements in surgical techniques, diagnostic tools and chemotherapeutic diversity, pancreatic cancer still remains to be a major problem with a high mortality rate. Metastasis, CSC existence and chemotherapeutic resistance are leading causes of death. ${ }^{22}$ One of the underlying mechanisms of these events is known as Epithelial to Mesenchymal Transition (EMT), ${ }^{23}$ which is controlled by transcription factors including Snail, Slug and Twist. ${ }^{24}$

EMT is known to control metastasis by arranging the synthesis of migration and invasion-related proteins. ${ }^{25}$ Snail, Slug and Twist were reported as crucial regulators of 


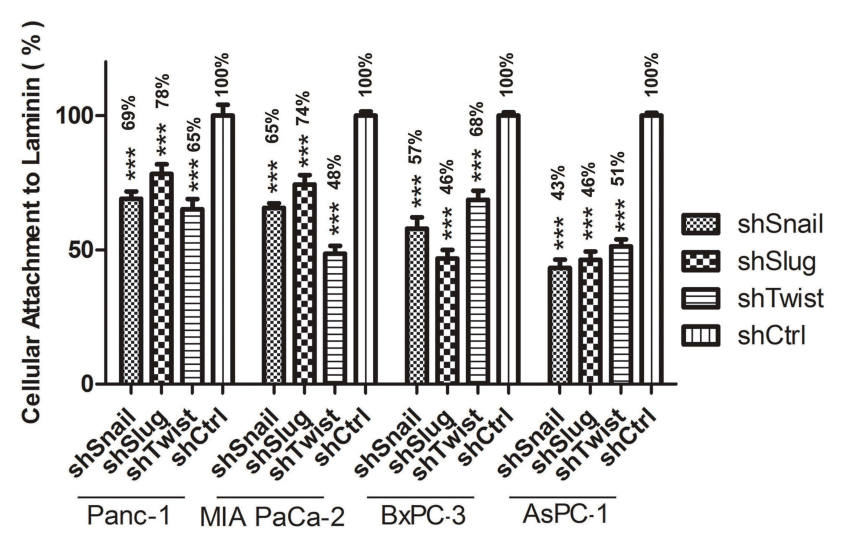

Figure 4 Attachment to laminin Graphical representation of Laminin attachment of EMT-ATF silenced Panc-I, MIA PaCa-2, BxPC-3 and AsPC-I cells and their negative controls. AsPC-I downregulated with EMT transcription factors show the least potential for laminin attachment compared to the other cell lines $(* * * p<0.00 I)$.

invasiveness and their increased expressions are associated with malignancy, ${ }^{26}$ and silencing these transcription factors was found to decrease invasiveness. Transmembrane invasion assay revealed that the knock-down of Snail, Slug and Twist reduced the invasiveness as stated in the previous studies made on adenocarcinomas. ${ }^{27-29}$ Compared to Slug and Twist, Snail showed a better potential for decreasing invaded cell numbers in all tested PC cell lines. EMT suppression decreased the expression levels of important invasion controllers including matrix metalloproteinase-1 (MMP-1), c-MET, Vimentin and N-Cadherin. The decreased expressions of these genes might also contribute to the overall decrease of invasive profile.

Snail, Slug and Twist are known to control the expression of integrins, including the receptor for laminin. ${ }^{11}$ In various cancer cell lines metastatic ability is found to be directly proportional to the level of laminin receptors on the cell surface. ${ }^{30}$ Laminin attachment assay revealed that cells showed less tendency to attach to laminin after EMTATF silencing. In a previous study by Sawai et al, AsPC-1 showed the highest laminin attachment capacity. ${ }^{31}$ After EMT-ATF silencing, AsPC-1 cells showed the least tendency to attach to the laminin-coated surface. CD44 is known to interact with ECM proteins, including laminin. $^{32}$ We observed that EMT-ATF silencing decreased the amount of CD44 in PC cells. The change in CD44 level might contribute to the decreased laminin attachment levels. Decreased invasion and laminin attachment reveal that Snail, Slug or Twist silencing are good candidates for overcoming the invasiveness of PC cells.

Another important property of an aggressive tumor is its migration capacity. The contributions of Snail, Slug and
Twist on migration were stated by various previous studies. $^{28,33}$ Snail, Slug and Twist are known to control migration by directly manipulating the synthesis of E-cadherin and N-cadherin. ${ }^{34,35}$ As a result of scratch and trans-well migration assays, wound healing and transmembrane migration ability of PC cells were decreased. Among the four cell lines, AsPC-1 showed the most promising decrease in migration. The loss of E-cadherin and the gain of N-cadherin are known to promote cellular motility. ${ }^{36}$ The greater decrease in the migration values of AsPC-1 might be correlated to the changes in N-cadherin and E-cadherin levels which were the highest compared to the other cell lines. Additionally, the decreased expressions of Zn-finger transcription factors Zeb-1, Zeb-2 (data not shown), c-met and vimentin may also be linked to the decrease in migration. $^{37-39}$ The decrease in migration and invasion after EMT-ATF silencing suggests that it is possible to overwhelm the highly metastatic character of PDACs. The individual silencing of Snail, Slug and Twist was not sufficient to stop cancer cell migration completely. Migration is a complex process controlled by many upstream elements, ${ }^{40}$ thus complete inhibition of migration requires knocking-out multiple pathways.

EMT has a role in cancer stem-like cell formation. ${ }^{41}$ Cancer stem cells in a tumor are responsible for selfrenewal and the maintenance of tumor growth. ${ }^{42}$ Increased expression levels of Snail, ${ }^{43} \mathrm{Slug}^{44}$ and Twist $^{28}$ were previously associated with tumor-sphere formation. We investigated the levels of PC specific cancer stem-like cell markers including CD24, CD133, EpCAM and CXCR4 to evaluate the effect of EMT down-regulation on CSCs. ${ }^{45}$ As found by others, CD44 contributes cancer stemness ${ }^{46}$ and, together with CD133, is associated with the tumor-sphere formation ${ }^{47}$ which is one of the key properties of CSCs. ${ }^{48}$ Snail, Slug, and Twist silenced PC cells have shown reduced potential to create tumor spheres as indicated in tumor sphere formation assay. Along with being fewer numerically, tumor sphere sizes were smaller in EMT silenced groups due to the decrease in self-renewal capacity, which is a characteristic of cancer stem-like cells. Additionally, CD24 and CXCR4 are accepted as PC specific CSC markers. ${ }^{49-51}$ We have found that the expression levels of CD24, CD44, CD133, CXCR4 were significantly decreased with EMT-ATF silencing. Moreover, the expression levels of embryonic stem cell markers that contribute to cancer stemness and pancreatic carcinogenesis, including ${ }^{52}$ Oct4, Nanog, Sox 2 and cMYC, were found to be decreased with EMT-ATF silencing. ${ }^{53}$ As a result, 
A
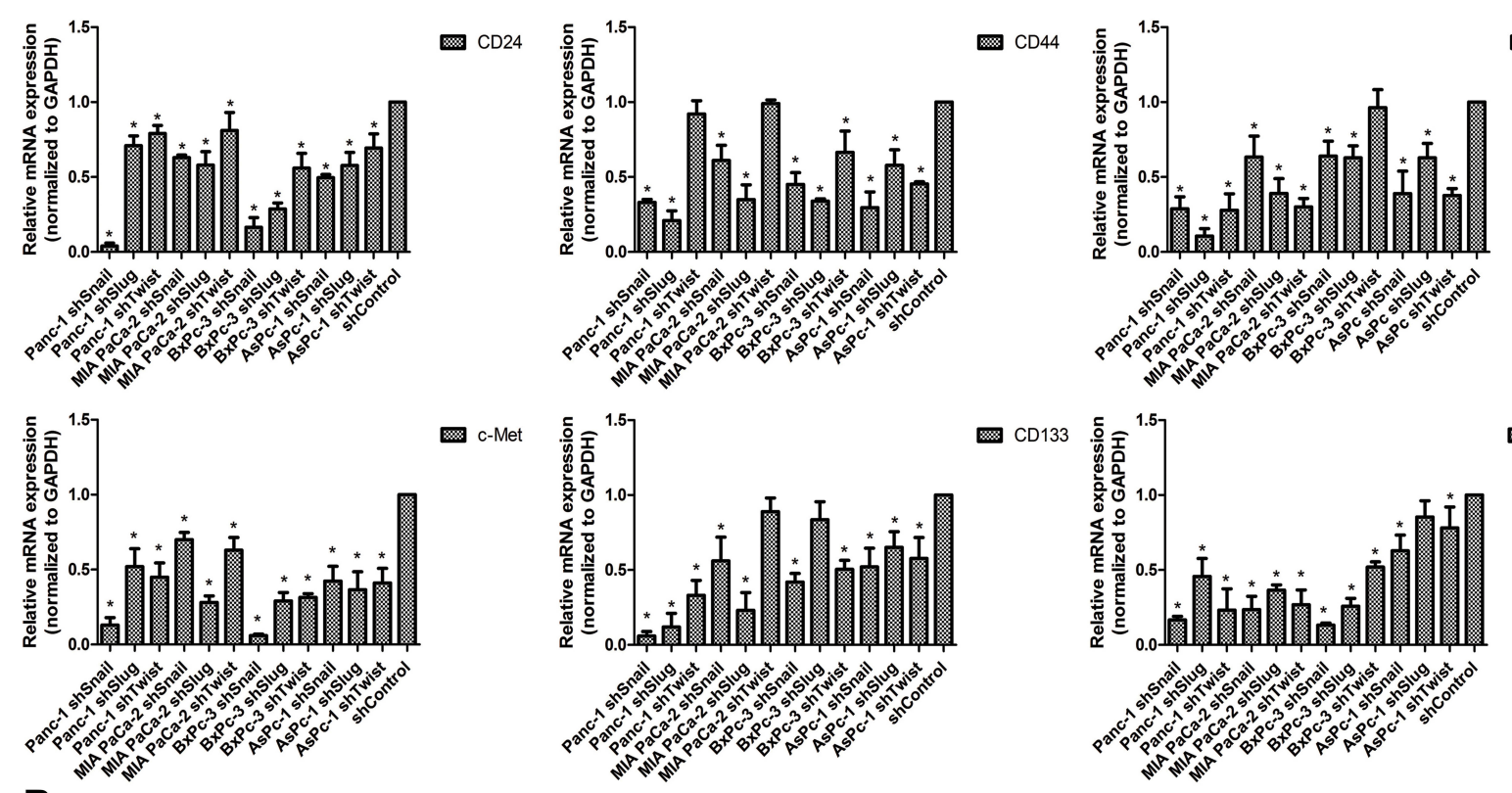

B
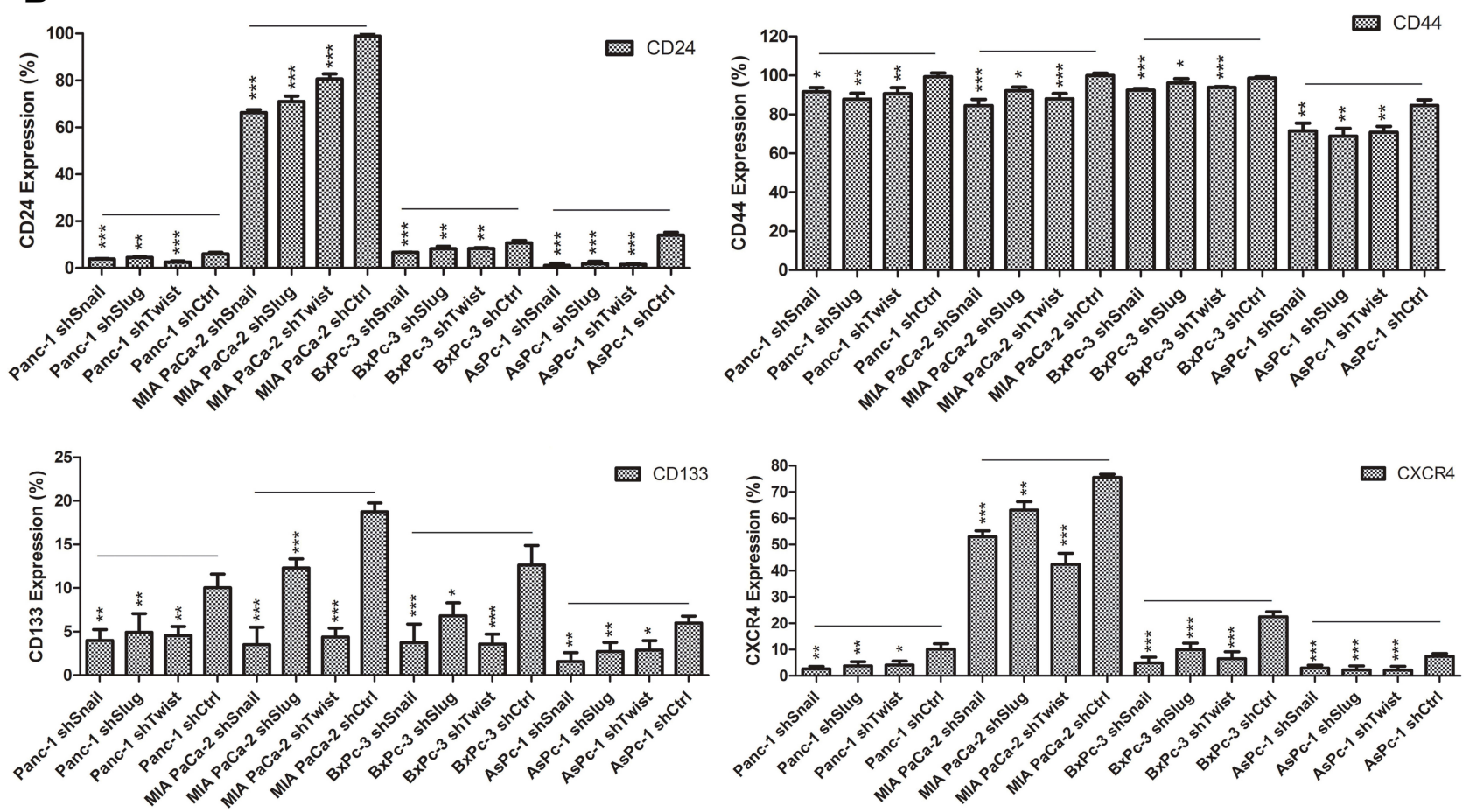

Figure 5 Differential expression of cancer stem-like cell markers of PC cells after EMT-ATF silencing Expression of stem-like cell surface markers in PC cell lines. (A) Expression of CD24, CD44, EpCAM, c-Met, CDI33 and CXCR4 were analyzed with qPCR. (B) Protein levels of CD24, CD44, CDI33 and CXCR4 were evaluated by FACS analysis. Experiments were repeated 3 times and statistical analysis was done $\left({ }^{*} p<0.05,{ }^{*} \mathrm{p}<0.01\right.$ and $\left.* * * p<0.001\right)$.

the decrease in cancer stemness caused by EMT-ATF silencing in AsPC-1 cells offers a better potential to decrease tumorigenesis and the aggressiveness of pancreatic cancer. Overall, AsPC-1 cells seemed a better candidate in the investigation of EMT silencing of PC tumorigenicity. The experiments for invasion, migration and laminin attachment have shown the best result in this cell line and it was used in the further experiments.

EMT has been shown to be a major contributor of drug resistance. ${ }^{54}$ To this end, we investigated how EMT contributes to the drug resistance of AsPC-1 and, to our knowledge, this is the first of any such analysis. AsPC-1 


\section{A shSnail shSlug shTwist shControl}
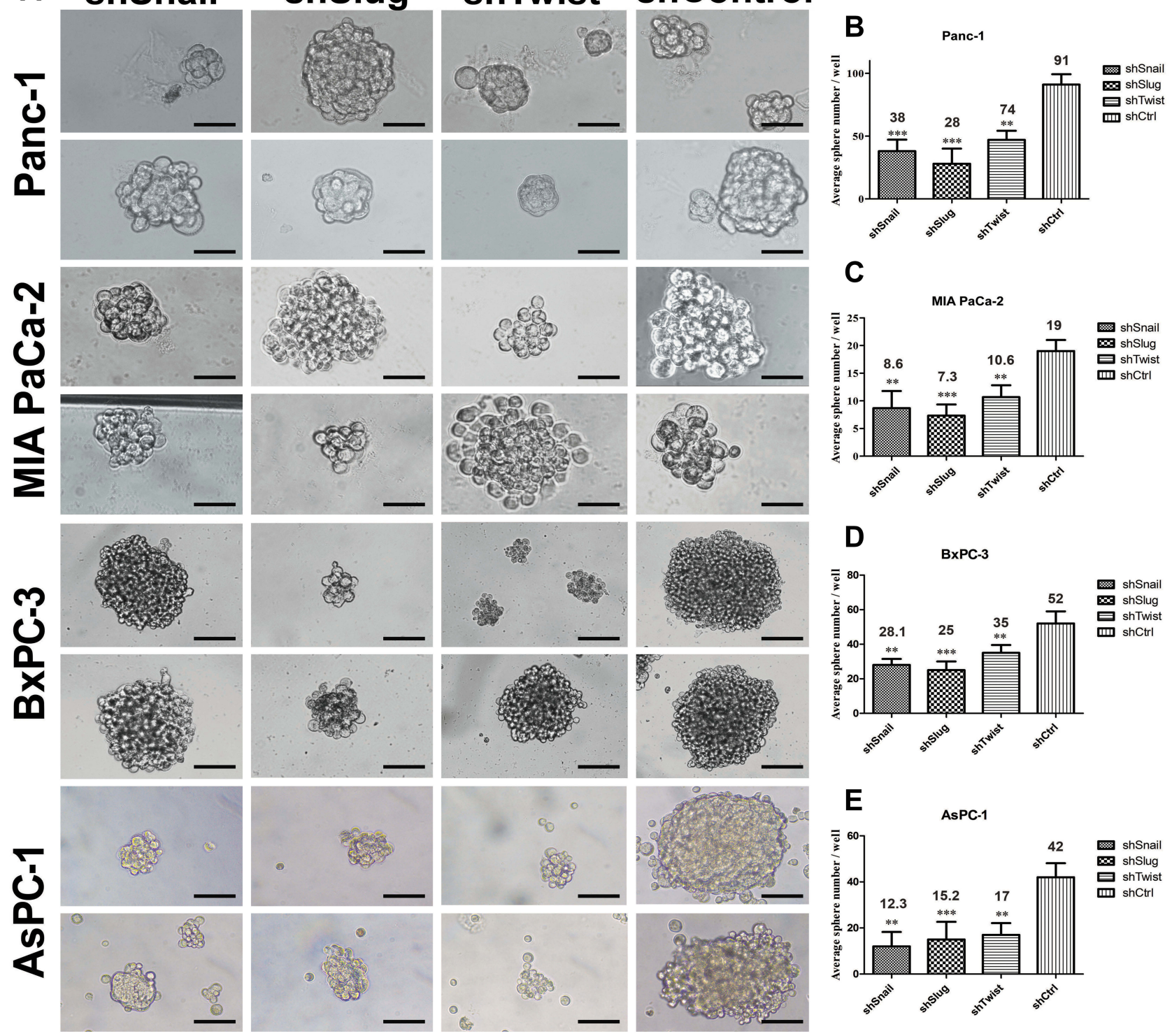

Figure 6 EMT-ATF silencing decreased the number and the size of tumor spheres. (A) Tumor sphere images of PC cells with EMT-ATF silencing and their controls. Cellular images were taken under a light microscope with 200x magnification and spheres (size $>50 \mu \mathrm{m})$ were counted. Graphical representation of an average number of spheres of Panc-I (B), MIA PaCa-2 (C), BxPC-3 (D) and AsPC-I (E) cells with gene silencing compared to their control (** $p<0.0 \mathrm{I}$ and $* * * p<0.00 \mathrm{I})$. The graph indicates the differences in average sphere numbers per well at $200 \times$ magnification. The values represent the mean \pm SD of triplicate samples from a single representative experiment $(n=9)$. Scale bar represents $100 \mu m$.

cells were treated with FDA approved pancreas cancer chemotherapeutics, 5-Fluorouracil and Mitomycin C. ${ }^{55}$ Compared to their control groups, the treatment groups showed less resistance to these drugs. The expression levels of drug resistance genes $\mathrm{ABCG} 2^{56}$ and Muc- $1,{ }^{57}$ and apoptosis inhibitor, Survivin, ${ }^{58}$ which are normally expressed in high amounts in AsPC-1 cells, ${ }^{59,60}$ were investigated after treatment. EMT regulates the expressions of $\mathrm{ABCG} 2^{61}$ and Muc- $1^{57}$ directly, and Survivin indirectly by manipulating the HIF-1 $\alpha$ pathway. ${ }^{62}$ Without drug induction, EMT-ATF silencing caused a decrease in the expression of these three genes. Following 5-Fluorouracil and Mitomycin-c induction, expressions of these genes were further decreased.

Additionally, we evaluated the effects of two small molecules: SD208, a TGF $\beta$ R1 blocker, ${ }^{63}$ and CX4945, a Casein Kinase-2 (CK2) inhibitor, ${ }^{15}$ on EMT associated gene expressions in AsPC-1 cells. CK2 controls the TGF $\beta 1$ induced cadherin switch and the TGF- $\beta$ pathway is the major controller of EMT. ${ }^{12,64}$ After treatment, expression levels of EMT related genes (Snail, Slug, Twist, E-cadherin, N-cadherin and Vimentin), PC stem 


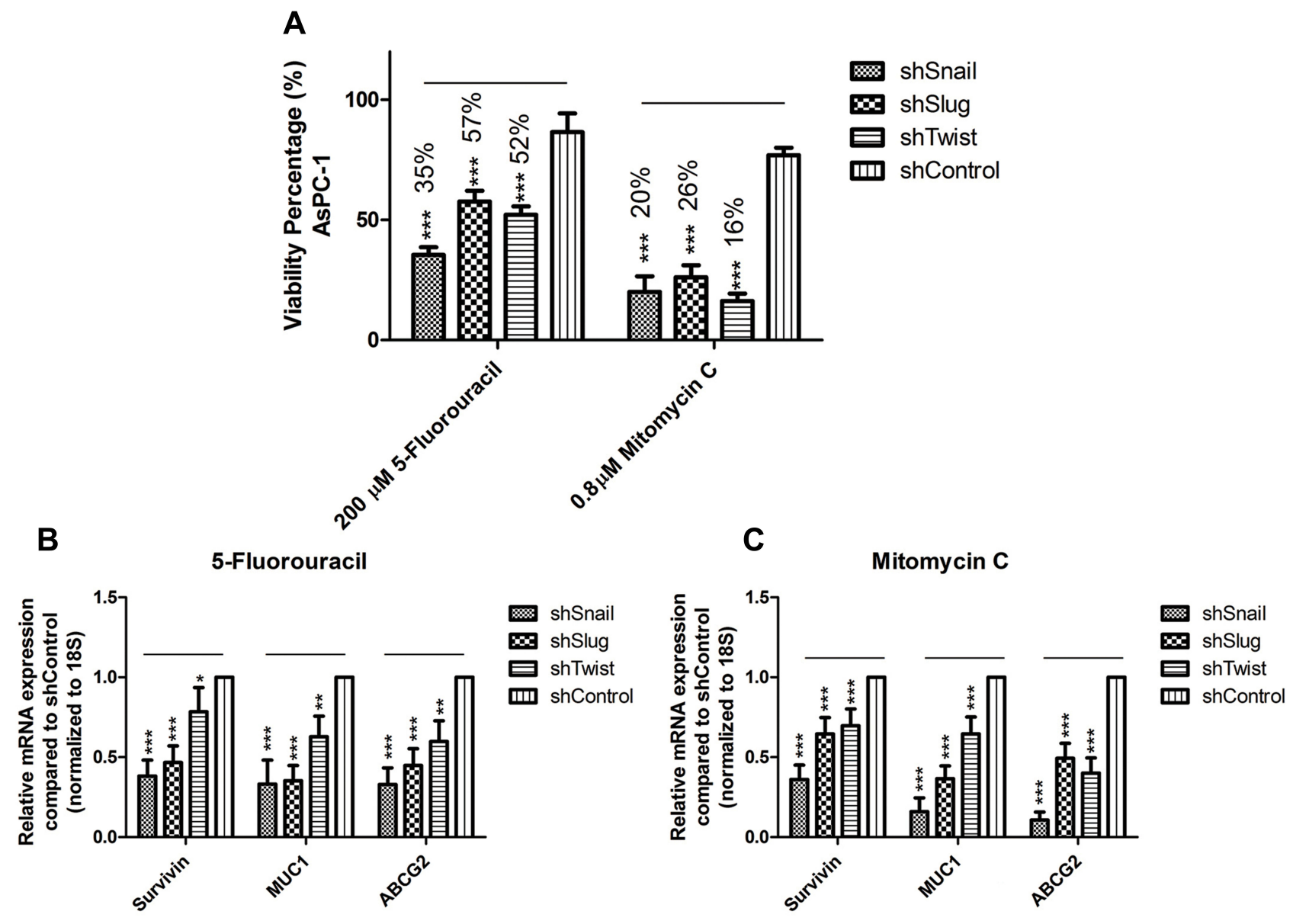

Figure 7 EMT-ATF silencing in AsPC-I cells decreased drug resistance. (A) Dose-dependent viability assay for AsPC-I cells against 5- Fluorouracil and Mitomycin C. Forty-eight hours of treatment with highest non-lethal doses decreased the viability values up to $50 \%$ when viability values for negative control groups were around $80 \%$. (B and $\mathbf{C}$ ) Expression values for drug resistance and survival genes ( $\mathrm{MUCI}, \mathrm{ABCG} 2$ and SURVIVIN) are found to be downregulated after 5-Fluorouracil and Mitomycin C treatment (***p $<0.00 \mathrm{I})$.

cell-specific markers (CD133, CXCR4, CD24, CD44 and EpCAM), pluripotency markers (Nanog, Klf4 and c-MYC) and metastasis-related markers (MMP1, MMP9, c-Met, MTA1 and MTA2) were investigated. A greater change in gene expressions was observed in Snail and Slug silenced AsPC-1 cells.

CX4945 $5^{64}$ and SD208 ${ }^{65}$ are known to control TGF- $\beta$ associated progression of prostate and lung cancer. We evaluated the effects of SD208, CX4945 and EMT-ATF silencing on migration and invasion. It was found that small molecule inhibitors have a positive effect on blocking migration. It was also recognized that when shSnail and shSlug cells were treated with small molecules, the amount of migrated cells were less compared to shControl cells treated with SD208 or CX-4945. Additionally, it was seen that CX-4945 has a greater potential for overcoming migration compared to SD-208. As for invasion, a combination of the small molecule inhibitors and gene silencing caused a significant decrease in the invasion capacity of PC cells. Invaded cells silenced for Snail or Slug were especially lower in numbers compared to the control group when combined with CX4945. Overall combination studies suggest that it might be possible to overcome invasion and migration by EMT inhibition by utilizing genetic modifications and external agents. Even though the alterations in gene expression levels following SD-208 and CX-4945 treatments were close to each other, we can say that for treating metastasis, it is more suitable to use CX-4945 rather than SD-208. It is recognized also that EMT-ATF silencing cannot be replaced by using small molecule inhibitors of EMT.

\section{Conclusions}

In conclusion, the silencing of Snail, Slug and Twist in PC cells resulted in decreased expression of numerous genes that are associated with mesenchymal characteristics, 


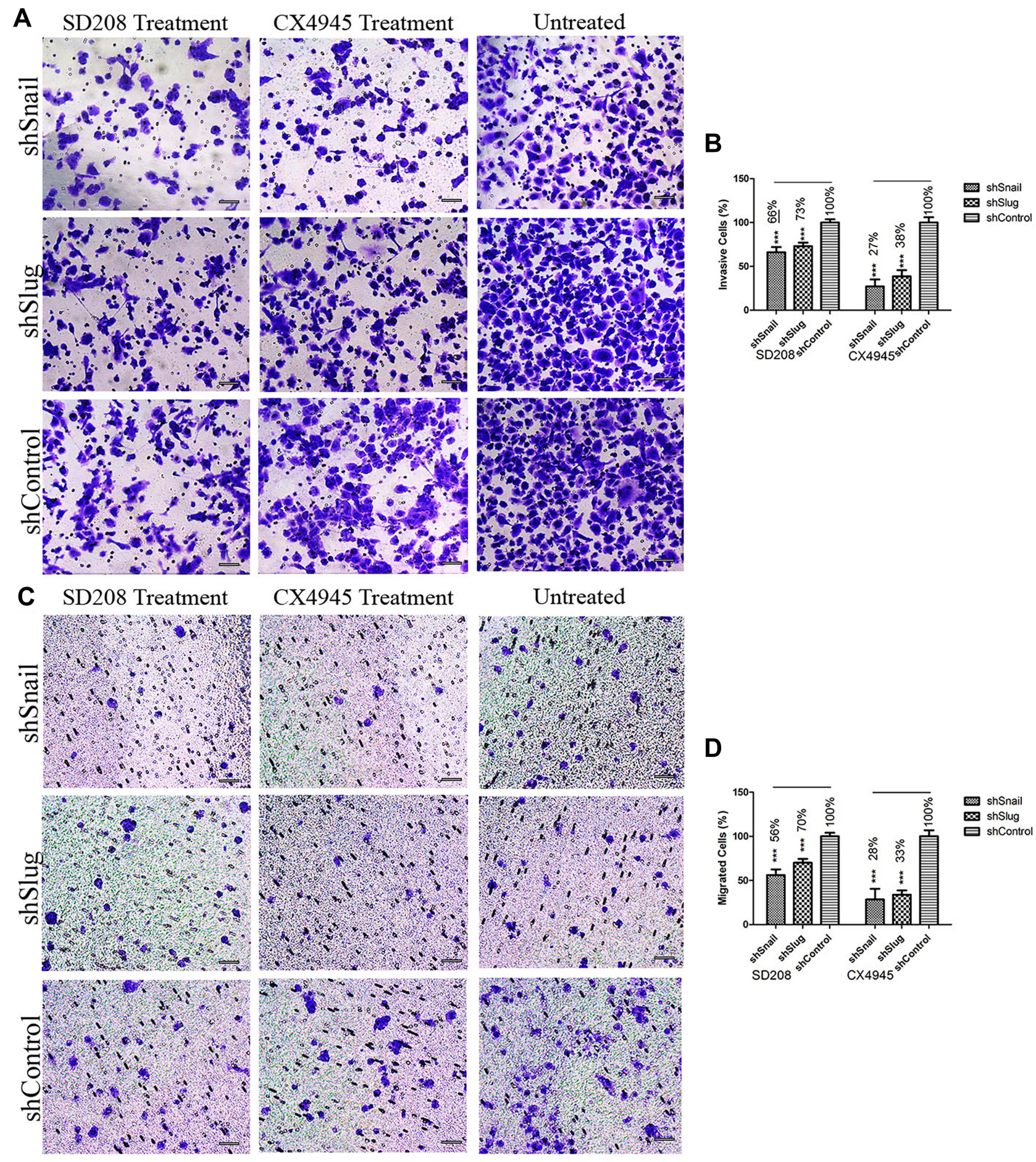

Figure 8 EMT-ATF silencing accompanied by small molecule inhibitors decreases the invasiveness and mobility of AsPC-I cells Microscope images of invaded (A) and migrated (C) AsPC-I cells after different treatments. Graphical representation of invaded (B) and migrated $(\mathbf{D})$ cell percentages $(* * * * 00.00 \mathrm{I})$. Scale bar represents I00 $\mu \mathrm{m}$.

metastasis and cancer stemness, which contributes to the prognosis of pancreatic cancer. Additionally, suppression of EMT is found to decrease the resistance towards FDA approved drugs that are used in treatment. Consequently, increasing the effects of EMT-ATF silencing by combination with agents such as CX4945 and SD208 could be a promising treatment option in the management of pancreatic cancer. Bioavailability of these small molecules increase their potential to be used in in vivo studies prior to preclinical applications for pancreatic cancer. 


\section{Abbreviations}

EMT, epithelial to mesenchymal transition; ATF, activating transcription factor; PC, Pancreatic cancer; MET, mesenchymal to epithelial transition; TGF-B, tumor growth factorbeta; MMPs, matrix metalloproteases; ZEB, ZEB1 - Zinc finger E-box-binding homeobox; EGF, epithelial growth factor.

\section{Data Sharing Statement}

The datasets during and/or analyzed during the current study available from the corresponding author on reasonable request.

\section{Ethical Approval}

This article does not contain any studies with human participants or animals performed by any of the authors. Cells used in the study are purchased from the American Type Culture Collection (ATCC). This study does not include any other cell line or primary cells that require ethical approval.

\section{Acknowledgments}

The authors would like to thank Ayla Burcin Asutay and Murat Ozpolat for their technical assistance in flow cytometry experiments. The authors would like to thank Evren Kasikci for editing and reviewing the manuscript.

\section{Author Contributions}

All authors made substantial contributions to conception and design, acquisition of data, or analysis and interpretation of data; took part in drafting the article or revising it critically for important intellectual content; gave final approval of the version to be published; and agree to be accountable for all aspects of the work.

\section{Funding}

This study was funded by the Yeditepe University Internal Research Fund.

\section{Disclosure}

The authors declare that they have no conflict of interest.

\section{References}

1. Bray F, Ferlay J, Soerjomataram I, et al. Global cancer statistics 2018: GLOBOCAN estimates of incidence and mortality worldwide for 36 cancers in 185 countries. CA Cancer J Clin. 2018;68(6):394-424. doi:10.3322/caac. 21492

2. Rawla P, Sunkara T, Gaduputi V. Epidemiology of pancreatic cancer: global trends, etiology and risk factors. World J Oncol. 2019;10(1):10. doi:10.14740/wjon 1166
3. Wang Z, Li Y, Ahmad A, et al. Pancreatic cancer: understanding and overcoming chemoresistance. Nat Rev Gastroenterol Hepatol. 2011;8 (1):27-33. doi:10.1038/nrgastro.2010.188

4. Groot VP, Gemenetzis G, Blair AB, et al. Implications of the pattern of disease recurrence on survival following pancreatectomy for pancreatic ductal adenocarcinoma. Ann Surg Oncol. 2018;25 (8):2475-2483. doi:10.1245/s10434-018-6558-7

5. Schrag D. Optimizing treatment for locally advanced pancreas cancer: progress but no precision. JAMA. 2016;315(17):1837-1838. doi:10.1001/jama.2016.4284

6. Liu T, Fang Y, Zhang H, et al. HEATR1 negatively regulates Akt to help sensitize pancreatic cancer cells to chemotherapy. Cancer Res. 2016;76(3):572-581. doi:10.1158/0008-5472.CAN-15-0671

7. Whittle MC, Izeradjene K, Rani PG, et al. RUNX3 controls a metastatic switch in pancreatic ductal adenocarcinoma. Cell. 2015;161(6):1345-1360. doi:10.1016/j.cell.2015.04.048

8. Steinbichler TB, Savic D, Dudás J, et al. Cancer stem cells and their unique role in metastatic spread. Paper presented at: Seminars in cancer biology. 2020.

9. Pastushenko I, Blanpain C. EMT transition states during tumor progression and metastasis. Trends Cell Biol. 2019;29(3):212-226. doi:10.1016/j.tcb.2018.12.001

10. Bacci M, Ippolito L, Magnelli L, Giannoni E, Chiarugi P Stromalinduced mitochondrial re-education: impact on epithelial-tomesenchymal transition and cancer aggressiveness. Paper presented at: Seminars in cell \& developmental biology. 2020.

11. Lamouille S, $\mathrm{Xu} \mathrm{J}$, Derynck R. Molecular mechanisms of epithelial-mesenchymal transition. Nat Rev Mol Cell Biol. 2014;15 (3):178-196. doi: $10.1038 / \mathrm{nrm} 3758$

12. Xu J, Lamouille S, Derynck R. TGF-beta-induced epithelial to mesenchymal transition. Cell Res. 2009;19(2):156-172. doi:10. 1038/cr.2009.5

13. Mohammad KS, Javelaud D, Fournier PG, et al. TGF-beta-RI kinase inhibitor SD-208 reduces the development and progression of melanoma bone metastases. Cancer Res. 2011;71(1):175-184. doi:10.1158/ 0008-5472.CAN-10-2651

14. Singh NN, Ramji DP. Transforming growth factor-beta-induced expression of the apolipoprotein $\mathrm{E}$ gene requires c-Jun N-terminal kinase, $\mathrm{p} 38$ kinase, and casein kinase 2. Arterioscler Thromb Vasc Biol. 2006;26 (6):1323-1329. doi:10.1161/01.ATV.0000220383.19192.55

15. Siddiqui-Jain A, Drygin D, Streiner N, et al. CX-4945, an orally bioavailable selective inhibitor of protein kinase CK2, inhibits prosurvival and angiogenic signaling and exhibits antitumor efficacy. Cancer Res. 2010;70(24):10288-10298. doi:10.1158/0008-5472.CAN-10-1893

16. Park HR, Jung WW, Kim HS, Bacchini P, Bertoni F, Park YK. Overexpression of metastatic tumor antigen in osteosarcoma: comparison between conventional high-grade and central low-grade osteosarcoma. Cancer Res Treat. 2005;37(6):360-364. doi:10.4143/ crt.2005.37.6.360

17. Liang CC, Park AY, Guan JL. In vitro scratch assay: a convenient and inexpensive method for analysis of cell migration in vitro. Nat Protoc. 2007;2(2):329-333. doi:10.1038/nprot.2007.30

18. Gaviraghi M, Tunici P, Valensin S, et al. Pancreatic cancer spheres are more than just aggregates of stem marker-positive cells. Biosci Rep. 2011;31(1):45-55. doi:10.1042/BSR20100018

19. Tominaga H, Ishiyama M, Ohseto F, et al. A water-soluble tetrazolium salt useful for colorimetric cell viability assay. Anal Commun. 1999;36(2):47-50. doi:10.1039/a809656b

20. Schneider CA, Rasband WS, Eliceiri KW. NIH Image to ImageJ: 25 years of image analysis. Nat Methods. 2012;9(7):671. doi:10.1038/ nmeth.2089

21. Möller B, Glaß M, Misiak D, Posch S. MiToBo-a toolbox for image processing and analysis. J Open Res Software. 2016;4:1.

22. Vincent A, Herman J, Schulick R, Hruban RH, Goggins M. Pancreatic cancer. The Lancet. 2011;378(9791):607-620. doi:10.1016/S01406736(10)62307-0 
23. Wang Y, Zhou BP. Epithelial-mesenchymal transition in breast cancer progression and metastasis. Chin J Cancer. 2011;30(9):603-611. doi:10.5732/cjc.011.10226

24. Kalluri R, Weinberg RA. The basics of epithelial-mesenchymal transition. J Clin Invest. 2009;119(6):1420-1428. doi:10.1172/ JCI39104

25. Derynck R, Weinberg RA. EMT and cancer: more than meets the eye. Dev Cell. 2019;49(3):313-316. doi:10.1016/j.devcel.2019.04.026

26. Wu J, Zhang Y, Cheng R, et al. Expression of epithelial-mesenchymal transition regulators TWIST, SLUG and SNAIL in follicular thyroid tumours may relate to widely invasive, poorly differentiated and distant metastasis. Histopathology. 2019;74(5):780-791. doi:10.11 11/his. 13778

27. Shih J-Y, Tsai M-F, Chang T-H, et al. Transcription repressor slug promotes carcinoma invasion and predicts outcome of patients with lung adenocarcinoma. Clin Cancer Res. 2005;11(22):8070-8078. doi:10.1158/1078-0432.CCR-05-0687

28. Wang Y, Liu J, Ying X, Lin PC, Zhou BP. Twist-mediated epithelial-mesenchymal transition promotes breast tumor cell invasion via inhibition of Hippo pathway. Sci Rep. 2016;6(1):24606. doi:10.1038/srep24606

29. Yang X, Han M, Han H, et al. Silencing Snail suppresses tumor cell proliferation and invasion by reversing epithelial-to-mesenchymal transition and arresting $\mathrm{G} 2 / \mathrm{M}$ phase in non-small cell lung cancer. Int J Oncol. 2017;50(4):1251-1260. doi:10.3892/ijo.2017.3888

30. Maltseva D, Rodin S. Laminins in metastatic cancer. Mol Biol. 2018;52(3):350-371. doi:10.1134/S0026893318030093

31. Sawai H, Yamamoto M, Okada Y, et al. Alteration of integrins by interleukin-1alpha in human pancreatic cancer cells. Pancreas. 2001;23(4):399-405. doi:10.1097/00006676-200111000-00011

32. Chen C, Zhao S, Karnad A, Freeman JW. The biology and role of CD44 in cancer progression: therapeutic implications. J Hematol Oncol. 2018;11(1):64. doi:10.1186/s13045-018-0605-5

33. Acikgoz E, Tatar C, Oktem G. Triptolide inhibits CD133+/CD44+ colon cancer stem cell growth and migration through triggering apoptosis and represses epithelial-mesenchymal transition via downregulating expressions of snail, slug, and twist. $J$ Cell Biochem. 2020;121(5-6):3313-3324. doi:10.1002/jcb.29602

34. Cano A, Pérez-Moreno MA, Rodrigo I, et al. The transcription factor snail controls epithelial-mesenchymal transitions by repressing E-cadherin expression. Nat Cell Biol. 2000;2(2):76. doi:10.1038/ 35000025

35. Yu L, Li H-Z, Lu S-M, et al. Down-regulation of TWIST decreases migration and invasion of laryngeal carcinoma Hep-2 cells by regulating the E-cadherin, N-cadherin expression. $J$ Cancer Res Clin Oncol. 2011;137(10):1487. doi:10.1007/s00432-011-1023-z

36. Loh C-Y, Chai JY, Tang TF, et al. The E-cadherin and N-cadherin switch in epithelial-to-mesenchymal transition: signaling, therapeutic implications, and challenges. Cells. 2019;8(10):1118. doi:10.3390/ cells 8101118

37. Peinado H, Olmeda D, Snail CA. Zeb and bHLH factors in tumour progression: an alliance against the epithelial phenotype? Nat Rev Cancer. 2007;7(6):415-428. doi:10.1038/nrc2131

38. Xiang C, Chen J, Fu P. HGF/Met signaling in cancer invasion: the impact on cytoskeleton remodeling. Cancers. 2017;9(5):44. doi:10.33 90/cancers 9050044

39. Sliogeryte K, Gavara N. Vimentin plays a crucial role in fibroblast ageing by regulating biophysical properties and cell migration. Cells. 2019;8(10):1164. doi:10.3390/cells8101164

40. Frank TS, Sun X, Zhang Y, et al. Genomic profiling guides the choice of molecular targeted therapy of pancreatic cancer. Cancer Lett. 2015;363(1):1-6. doi:10.1016/j.canlet.2015.04.009

41. Chen T, You Y, Jiang H, Wang ZZ. Epithelial-mesenchymal transition (EMT): a biological process in the development, stem cell differentiation, and tumorigenesis. J Cell Physiol. 2017;232 (12):3261-3272. doi:10.1002/jcp.25797
42. Yadav AK, Desai NS. Cancer stem cells: acquisition, characteristics, therapeutic implications, targeting strategies and future prospects. Stem Cell Rev Rep. 2019;15(3):331-355. doi:10.1007/s12015-01909887-2

43. Zhou W, Lv R, Qi W, et al. Snail contributes to the maintenance of stem cell-like phenotype cells in human pancreatic cancer. PLoS One. 2014;9(1):e87409. doi:10.1371/journal.pone.0087409

44. Luanpitpong S, Li J, Manke A, et al. SLUG is required for SOX9 stabilization and functions to promote cancer stem cells and metastasis in human lung carcinoma. Oncogene. 2016;35(22):2824. doi:10.1038/onc.2015.351

45. Gzil A, Zarębska I, Bursiewicz W, Antosik P, Grzanka D, Szylberg Ł. Markers of pancreatic cancer stem cells and their clinical and therapeutic implications. Mol Biol Rep. 2019;1-17.

46. Yan Y, Zuo X, Wei D. Concise review: emerging role of CD44 in cancer stem cells: a promising biomarker and therapeutic target. Stem Cells Transl Med. 2015;4(9):1033-1043. doi:10.5966/sctm.20150048

47. Li Z. CD133: a stem cell biomarker and beyond. Exp Hematol Oncol. 2013;2(1):17. doi:10.1186/2162-3619-2-17

48. Guo W, Lasky JL, Wu H. Cancer stem cells. Pediatr Res. 2006;59 (S4):59R. doi:10.1203/01.pdr.0000203592.04530.06

49. Chatterjee S, Behnam Azad B, Nimmagadda S. The intricate role of CXCR4 in cancer. Adv Cancer Res. 2014;124:31-82.

50. Jaggupilli A, Elkord E. Significance of CD44 and CD24 as cancer stem cell markers: an enduring ambiguity. Clin Dev Immunol. 2012;2012.

51. Salaria S, Means A, Revetta F, Idrees K, Liu E, Shi C. Expression of CD24, a stem cell marker, in pancreatic and small intestinal neuroendocrine tumors. Am J Clin Pathol. 2015;144(4):642-648. doi:10.1309/AJCPMZY5P9TWNJJV

52. Müller M, Hermann PC, Liebau S, et al. The role of pluripotency factors to drive stemness in gastrointestinal cancer. Stem Cell Res. 2016;16(2):349-357. doi:10.1016/j.scr.2016.02.005

53. Ocaña $\mathrm{OH}$, Nieto MA. Epithelial plasticity, stemness and pluripotency. Cell Res. 2010;20(10):1086-1088. doi:10.1038/ cr.2010.127

54. Shibue T, Weinberg RA. EMT, CSCs, and drug resistance: the mechanistic link and clinical implications. Nat Rev Clin Oncol. 2017;14(10):611. doi:10.1038/nrclinonc.2017.44

55. Aiura K, Takahashi S, Matsui J, Ueda M, Kitagawa Y. Corrigendum to "Beneficial effects of 5-fluorouracil and heparinbased portal infusion chemotherapy combined with mitomycin $\mathrm{C}$ and cisplatin after curative resection of pancreatic cancer"'Pancreatology 10 (2010) 250-258](S1424390316312637) (10.1016/j. pan. 2016.12. 014). Pancreatology. 2017;17 (2):151-152. doi:10.1016/j.pan.2016.12.014

56. Mo W, Zhang J-T. Human ABCG2: structure, function, and its role in multidrug resistance. Int J Biochem Mol Biol. 2012;3(1):1.

57. Nath S, Mukherjee P. MUC1: a multifaceted oncoprotein with a key role in cancer progression. Trends Mol Med. 2014;20(6):332-342. doi:10.1016/j.molmed.2014.02.007

58. Akhtar M, Gallagher L, Rohan S. Survivin: role in diagnosis, prognosis, and treatment of bladder cancer. Adv Anat Pathol. 2006;13 (3):122-126. doi:10.1097/00125480-200605000-00003

59. Roh YJ, Kim JH, Kim I-W, Na K, Park JM, Choi M-G. Photodynamic therapy using photosensitizer-encapsulated polymeric nanoparticle to overcome ATP-binding cassette transporter subfamily G2 function in pancreatic cancer. Mol Cancer Ther. 2017;molcanther. 0642.2016.

60. Kami K, Doi R, Koizumi M, et al. Survivin expression is a prognostic marker in pancreatic cancer patients. Surgery. 2004;136(2):443-448.

61. Mato E, Gonzalez C, Moral A, et al. ABCG2/BCRP gene expression is related to epithelial-mesenchymal transition inducer genes in a papillary thyroid carcinoma cell line (TPC-1). $J$ Mol Endocrinol. 2014;52(3):289-300. doi:10.1530/JME-14-0051 
62. Sanhueza C, Wehinger S, Castillo Bennett J, Valenzuela M, Owen GI, Quest AF. The twisted survivin connection to angiogenesis. Mol Cancer. 2015;14(1):198. doi:10.1186/s12943-015-0467-1

63. Manaenko A, Lekic T, Barnhart M, Hartman R, Zhang JH. Inhibition of transforming growth factor-beta attenuates brain injury and neurological deficits in a rat model of germinal matrix hemorrhage. Stroke. 2014;45(3):828-834. doi:10.1161/STROKEAHA.113.003754
64. Kim J, Hwan Kim S. CK2 inhibitor CX-4945 blocks TGF-beta1induced epithelial-to-mesenchymal transition in A549 human lung adenocarcinoma cells. PLoS One. 2013;8(9):e74342. doi:10.1371/ journal.pone. 0074342

65. Fournier PG, Juarez P, Jiang G, et al. The TGF-beta signaling regulator PMEPA1 suppresses prostate cancer metastases to bone. Cancer Cell. 2015;27(6):809-821. doi:10.1016/j.ccell.2015.04.009

\section{Publish your work in this journal}

OncoTargets and Therapy is an international, peer-reviewed, open access journal focusing on the pathological basis of all cancers, potential targets for therapy and treatment protocols employed to improve the management of cancer patients. The journal also focuses on the impact of management programs and new therapeutic

Submit your manuscript here: https://www.dovepress.com/oncotargets-and-therapy-journal agents and protocols on patient perspectives such as quality of life, adherence and satisfaction. The manuscript management system is completely online and includes a very quick and fair peer-review system, which is all easy to use. Visit http://www.dovepress.com/ testimonials.php to read real quotes from published authors. 